\title{
Penerapan Sistem Informasi Data TPM yang Terpusat Menggunakan Media Interaktif
}

\author{
Dianta Mustofa Kamal $^{1 *}$, Seto Tjahyono ${ }^{2}$, Yuli Mafendro DES ${ }^{2}$, Windu Asri Mumpuni ${ }^{2}$ \\ ${ }^{1}$ Program Studi Magister Terapan Rekayasa Industri, Politeknik Negeri Jakarta, Depok, Indonesia \\ ${ }^{2}$ Program Studi Teknik Mesin Jurusan Teknik Mesin, Politeknik Negeri Jakarta, Depok, Indonesia \\ ('dianta@pnj.ac.id)
}

\begin{abstract}
Abstrak - Industri tidak terlepas dari aktivitas maintenance, data mengenai manajemen perawatan fasilitas menjadi penting untuk diketahui semua orang agar bisa selalu memantau kondisi equipment dan lingkungan pabrik apabila terjadi ketidaknormalan, banyak industri masih menggunakan metode konvensional (paper-based) dalam record perawatan, hal ini kurang efektif dan efisien. Tujuan penelitian ini adalah penerapan Sistem Informasi data TPM menggunakan media interaktif sebagai sentralisasi data. Media interaktif ini dibuat dengan memanfaatkan Google Apps seperti Google form, Google site, serta Google spreadsheet dan formula yang terdapat di dalamnya dan disatukan dalam bentuk website yang dikemas dalam bentuk QR code. Output yang dihasilkan yaitu website untuk menampilkan informasi mengenai jadwal dan prosedur perawatan mesin dan atau fokus area tertentu. Manajemen lebih mudah untuk menilai dan memberikan review terkait pekerjaan yang berhubungan dengan TPM di lapangan dengan lebih mudah.
\end{abstract}

Kata kunci: Google Apps; recording data; Total Productive Maintenance

\section{PENDAHULUAN}

Trend dan aktivitas maintenance yang berpengaruh pada keberlangsungan produksi dapat diketahui salah satunya melalui management perawatan fasilitas total productive maintenance (TPM). TPM memiliki delapan pilar yang sangat menunjang kegiatan maintenance perusahaan. Informasi yang ter-record dari kegiatan ini sangatlah penting sebagai data acuan dalam hal perawatan fasilitas. Pendataan TPM pada awalnya masih menggunakan metode konvensional yang berbasis kertas (paperbased) sehingga updating dan record keeping data masih belum tersentralisai, perawatannya sulit, tidak ramah lingkungan karena membutuhkan banyak kertas. Ditambah lagi potensi kehilangan data cukup besar, sehingga penerapan TPM berbasis sistem informasi menjadi sangat penting terutama bagi pabrik atau industri yang aktifitas maintenance-nya selalu dipantau dari waktu ke waktu.

Tujuan penelitian ini adalah mendesain media interaktif (interactive dashboard) yang dapat diterapkan pada industri sebagai sistem informasi data TPM terpusat agar memudahkan update dan record data terkait maintenance dan memudahkan manajemen dalam sarana pemberian review atau masukkan untuk pengembangan lebih lanjut di lapangan.

\section{STUDI LITERATUR}

Total Productive Maintenance (TPM) merupakan suatu aktivitas pemeliharaan pada industri dan perusahaan yang mengikutsertakan semua elemen dari perusahaan, yang bertujuan untuk menciptakan suasana kritis (critical mass) dalam lingkungan industri guna mencapai zero defect dan zero accident (Kurniawan,2013). Keterlibatan karyawan merupakan bagian penting dari proses TPM, tujuannya adalah untuk memanfaatkan keahlian dan kreativitas dari seluruh pekerja untuk menunjang performa pabrik. TPM mengharuskan karyawan untuk mengambil peran lebih aktif dalam hal perawatan serta kinerja pabrik, dalam TPM setiap karyawan pasti diamanati suatu kewajiban dalam hal maintenance dan semua upaya harus diarahkan ke tujuan pabrik (Venkatesh, 2007)

TPM menurut Venkatesh (2007) terdiri dari atas tiga buah suku kata, yaitu Total, mengidentifikasi bahwa TPM mempertimbangkan berbagai aspek dan melibatkan seluruh personil yang ada, mulai dari tingkatan atas hingga kejajaran yang bawah. Productive menitikberatkan pada segala usaha untuk mencoba melakukan pemeliharaan dengan kondisi produksi tetap berjalan dan meminimalkan masalah-masalah yang terjadi di produksi saat pemeliharaan dilakukan. Maintenance berarti memelihara dan menjaga peralatan agar selalu 
pada kondisi baik, yang dilakukan oleh operator produksi dengan selalu melakukan pembersihan, pelumasan, dan inspeksi.

TPM sendiri dapat diartikan hubungan kerjasama yang erat antara perawatan dan organisasi produksi secara menyeluruh bertujuan untuk meningkatkan kualitas produksi, mengurangi waste, mengurangi biaya produksi, meningkatkan kemampuan peralatan dan pengembangan dari keseluruhan sistem pemeliharaan pada perusahaan manufaktur (Venkatesh, 2007).

\section{METODOLOGI}

Metodologi yang digunakan dalam penelitian ini diawali dengan analisis kelebihan dan kekurangan terhadap empat konsep disain Interactive Dashboard TPM, yaitu:

1. KONSEP 1:

Membuat website menggunakan google site dan pelaporan finding melalui whatsapp oleh user kepada TPM officer. Konsep ini merupakan pembuatan interactive dashboard TPM dengan media pelaporan finding dari setiap user lapangan kepada TPM Officer melalui whatsapp untuk kemudian di-upload ke website tersebut.

Kelebihan:

a. Mudah digunakan oleh pengguna

b. Bisa dilakukan dimana saja dan kapan saja

c. Dapat digunakan oleh semua pihak tanpa menggunakan media lain untuk mengakses

\section{Kekurangan:}

a. Beban admin TPM terlalu besar, karena semua pelaporan dikerjakan oleh admin TPM

b. Resiko terdapat finding yang belum terupdate karena terlalu banyak

c. Proses pengerjaan yang lama

\section{KONSEP 2:}

Pembuatan interactive dashboard TPM dengan web based google site dan memberikan akses kepada setiap user untuk melakukan pengupdatean data terkait TPM.

Kelebihan:

a. Mudah melakukan perubahan pada data oleh user

b. Fleksibel dan efisien

c. Data akan lebih cepat ter-update

\section{Kekurangan :}

a. Hanya pengguna terdaftar yang dapat mengakses

b. Maintenance sistem yang sulit

\section{KONSEP 3:}

Membuat web based google site dan memberikan saran pemutakhiran data melalui workdir yang dapat diakses setiap user dan lebih mudah.

Kelebihan:

a. Mudah melakukan perubahan pada data oleh user

b. Fleksibel dan efisien

c. Data akan lebih cepat ter-update

Kekurangan:

Admin TPM harus meluangkan waktu untuk memindahkan data dari workdir ke website

4. KONSEP 4:

Membuat aplikasi android khusus untuk menunjang sentralisasi data dan pelaporan data-data terkait TPM Kelebihan:

a. Lebih canggih dan efisien dalam proses penggunaannya

b. Dapat difungsikan kapanpun dan dimanapun 
Kekurangan:

a. Membutuhkan data jaringan internet yang sustain

b. Sistem terlalu kompleks dan berbayar

\section{HASIL DAN DISKUSI}

Berdasarkan kelebihan dan kekurangan dari keempat konsep penerapan media interaktif tersebut maka Konsep 4 adalah konsep yang terbaik, yakni membuat aplikasi android khusus untuk menunjang sentralisasi data dan pelaporan data-data terkait TPM.

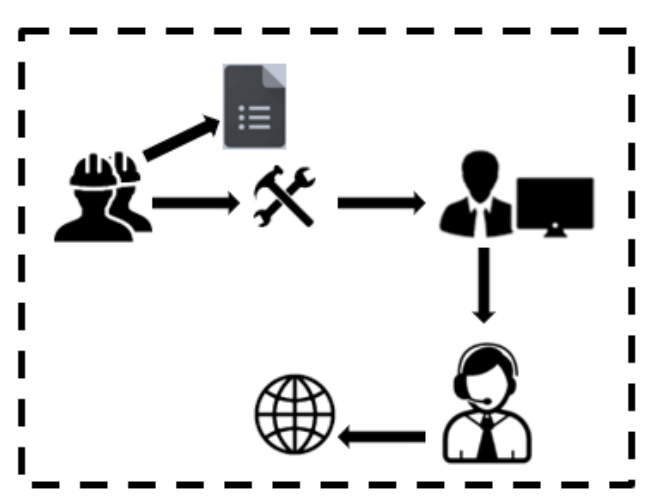

Gambar 1. Prinsip kerja aplikasi android khusus

Prinsip kerja dari Konsep 4 ini digambarkan pada Gambar 1 di atas. Dimulai dari pembuatan template dashboard web based google site sebagai media sentralisasi data, kemudian membuat folder di workdir yang berisikan format dari data apa saja yang akan di upload di website TPM, kemudian setiap user membuat pelaporan TPM tersebut di workdir untuk kemudian di upload dan disentralisasikan oleh TPM officer ke website TPM kemudian dikemas dalam sebuah QR code untuk setiap area di pabrik. Hasil Pembuatan Interactive Dashboard TPM

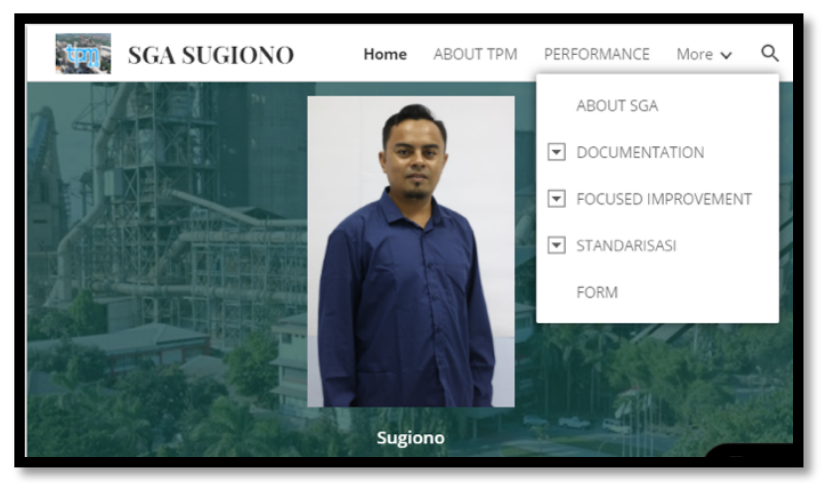

Gambar 2. Contoh tampilan muka layar interactive dashboard setiap departemen 


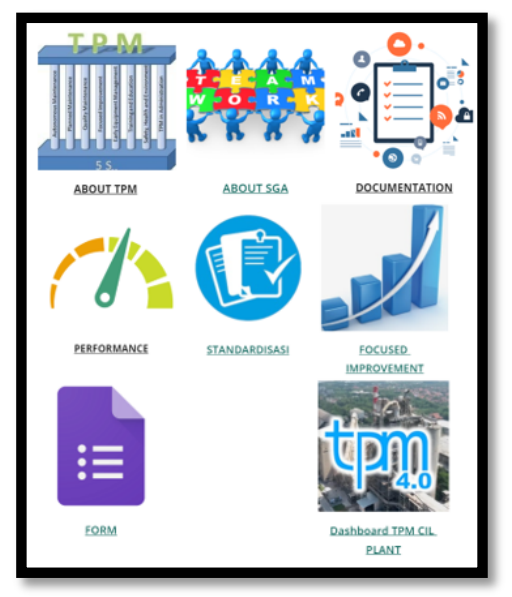

Gambar 3. Menu yang tersedia di website tiap unit

Penjelasan setiap menu:

a. Home: Halaman awal atau halaman pembuka yang berisikan menu dalam website tersebut.

b. About TPM: Berisi informasi mengenai TPM dan penjelasan setiap pilarnya.

c. Performance: Berisi informasi tentang hasil pencapaian setiap SGA

d. About SGA: Berisi informasi terkait SGA seperti struktur organisasi SGA, denah fokus area, skala prioritas fokus area, time line GEMBA.

e. Documentation: Berisikan foto-foto kegiatan GEMBA, review dari ketua SGA, ketua gugus, dan fasilitator, serta dokumentasi hasil autnomus maintenance setiap fokus area.

f. Focus Improvement :Berisikan data laporan focus improvement yang telah dibuat SGA tersebut.

g. Standarisasi: Berisi informasi terkait standard dari setiap fokus departemen

h. Form: Berisi form dan daftar absesnsi kehadiran

i. Dashboard TPM: Tersambung dengan website informasi sentral untuk seluruh departemen

Untuk memudahkan pengguna, dibuatlah diagram alir proses penggunaan interactive dashboard TPM ini yaitu:

1. Scan QR code yang tertempel pada masing-masing focus area untuk masuk ke dalam website.

2. Apabila ingin melakukan pengecekan atau mencari data, segala informasi tersedia dalam website seperti data temuan keabnormalitasan, focused improvement, standard 5R, dan CLIT.

3. Apabila ada masukkan, feedback, dan sebagainya bisa disampaikan melalui form review yang terdapat di menu documentation.

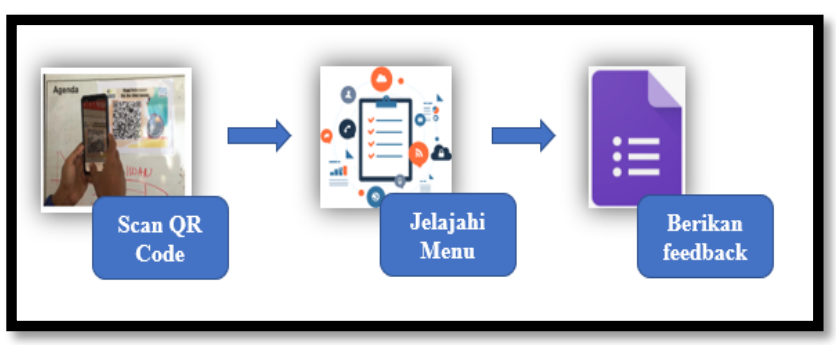

Gambar 4. Alur proses penggunaan interactive dashboard

Media Interaktif ini sudah didesain dan diterapkan pada salah satu industri semen terkemuka di Indonesia untuk melaksanakan TPM yang terpusat. Kondisi setelah dilakukan pembuatan Interactive Dashboard sebagaimana dijelaskan dalam Tabel 1. 
Tabel 1

Kondisi sebelum dan sesudah dibuat interactive dashboard

\begin{tabular}{|c|c|c|}
\hline Kategori & Sebelum & Sesudah \\
\hline Media sentralisasi data & Paperbased & Website \\
\hline Proses update data & $\begin{array}{l}\text { Mandiri, harus ganti } \\
\text { kertas }\end{array}$ & Bersama, Autosave \\
\hline Proses mencari data & $\begin{array}{l}\text { Membuka lembaran- } \\
\text { lembaran data }\end{array}$ & Lihat di website \\
\hline Perawatan sistem & $\begin{array}{l}\text { Kurang, kertas mudah } \\
\text { hilang dan rusak }\end{array}$ & $\begin{array}{l}\text { Data aman tersimpan di } \\
\text { website }\end{array}$ \\
\hline $\begin{array}{l}\text { Proses pemberian review dari } \\
\text { management }\end{array}$ & Lisan, dan tidak terekam & $\begin{array}{l}\text { Google form dan terekam } \\
\text { setiap waktunya }\end{array}$ \\
\hline Sentralisasi data & $\begin{array}{l}\text { Tidak semua orang bisa } \\
\text { mengakses }\end{array}$ & $\begin{array}{l}\text { Semua orang bisa } \\
\text { mengakses data kapanpun }\end{array}$ \\
\hline Informasi yang tersedia & $\begin{array}{l}\text { Hanya mengenai } \\
\text { kebersihan equipment dan } \\
\text { lingkungan kerja }\end{array}$ & $\begin{array}{l}\text { Mengenai kebersihan, } \\
\text { improvement, finding } \\
\text { temuan, dan komitmen. }\end{array}$ \\
\hline
\end{tabular}

\section{KESIMPULAN}

Berdasarkan dari hasil penelitian disain media interaktif untuk sentralisasi data TPM (Total Productive Maintenance) dapat disimpulkan:

1. Penggunaan interactive dashboard TPM dinilai mampu memudahkan proses update dan review kegiatan yang menunjang proses maintenance.

2. Web based google spreadsheet dipilih untuk pembuatan interactive dashboard ini karena sesuai dengan kebutuhan pengguna dan kriteria yang telah ditetapkan yaitu user friendly, proses maintenance sistem yang mudah, dan informatif.

3. Dengan adanya interactive dashboard TPM ini, proses record keeping data terkait menjadi lebih berjalan, serta para management lebih mudah untuk menilai dan mereview segala kegiatan yang berkaitan dengan TPM di lapangan dalam satu genggaman saja.

\section{DAFTAR PUSTAKA}

Anonim, (2013), "Google Sites: Creating, editing, and sharing a site," Jurnal Umum.

Ansori, N. \& Mustajib, M. I. (2013). Sistem Perawatan Terpadu. Yogyakarta. Graha Ilmu.

Ariadi. (2011). Analisis Perancangan Kode Matriks Dua Dimensi Quick Response (QR) Code. Skripsi. Universitas Sumatera Utara.

Borris, Steven,2006,"Total Productive Maintenance", McGraw-hill, United State America.

Dtf, Ainun, (2020) Cara Membuat Google Forms. Diakses 18 Juli 2021 https://salamadian.com/cara-membuatgoogle-forms/

Fitriyani, Ananta. (2020). Cara Membuat Website Dengan Google Sites.

Ginting, Kristian. (2013). Small Group Activities. Diakses 19 Juli 2021 https://kaizenrms.wordpress.com/2013/01/25/small-group-activities-sga/

Google, (2009), "Google Sites Tutorial", Jurnal Umum

$\begin{array}{lllll}\text { Google. } & \text { (2021). } & \text { IMPORTRANGE. } & \text { Diakses } & 17\end{array}$ https://support.google.com/docs/answer/3093340?hl=id

Imai, M., (1986). Kaizen (Vol. 201). New York: Random House Business Division.

Imai, M., (2007). Gemba Kaizen. A commonsense, low-cost approach to management. In Das Summa Summarum des Management (pp. 7-15). Gabler.

Info Training Indonesia.2018. World Class TPM.Jakarta. Diakses 18 Juli 2021 https://infotrainingindonesia.com/training-tentang-world-class-totalpreventive-maintenance-tpm/

Ireland, F., \& Dale, B. G. (2001). A study of total productive maintenance implementation. 
Kurniawan, Fajar. (2013). Manajemen Perawatan Industri : Teknik dan Aplikasi Implementasi Total Productive Maintenance (TPM), Preventive Maintenance dan Reability Centered Maintenance (RCM). Yogyakarta : Graha Ilmu.

MaxiResearch, (2018) "Google Forms Tutorial," PT Mulia Karya Inovasi, Power Point-PDF, 2018.

Microsoft. (2021). Fungsi COUNTA. Diakses 9 April 2021 https://support.microsoft.com/id-id/office/countafungsi-counta-7dc98875d5c1-46f1-

Microsoft. (2021). Fungsi COUNTIFS. Diakses 9 April 2021 https://support.microsoft.com/idid/office/countifs-fungsi-countifsdda3dc6e-f74e-4aee-88bc-aa8c2a866842

Microsoft. (2021). Fungsi IF . Diakses pada 17 Mei 2021 https://support.microsoft.com/id-id/office/fungsi-if69aed7c9-4e8a-4755a9bc-aa8bbff73be2

Microsoft. (2021). Fungsi IF,AND, OR, NOT. Diakses pada 17 Mei 2021 https://support.microsoft.com/idid/office/menggunakan-if-dengan-fungsiand-or-dan-not-d895f58c-b36c-419e-b1f2-5c193a236d97

Microsoft. (2021). Fungsi SUMIFS. Diakses 6 April 2021 https://support.microsoft.com/id-id/office/sumifsfungsi-sumifs-c9e748f57ea7-455d-

Microsoft. (2021). Gambaran Umum Pivot Table dan Pivot chart. Diakses 17 Mei 2021.

Microsoft. (2021). HLOOKUP-fungsi HLOOKUP. Diakses pada 6 April 2021 https://support.microsoft.com/id-id/office/hlookup-fungsi-hlookup-a3034eecb719-4ba3-bb65e1ad662ed95f

Microsoft. (2021). VLOOKUP - fungsi VLOOKUP. Diakses pada 5 Mei https://support.microsoft.com/id-id/office/vlookup-fungsi-vlookup-0bbc808326fe-4963-8ab893a18ad188a1

Nakajima, Siichi.(1988). "Introduction to Total Productive Maintenance (TPM)": Cambridge. Massachussets. Osada, Takashi. (2004). Sikap Kerja 5S. Jakarta : PPM.

Roberto. (2015). Mempelajari Penerapan Total Productive Maintenance di Area Extruding Process pada PT INDAC INT'L BATTERY COMPONENT Indonesia.Bogor

Roger. C. Palmer. 2007.’The Bar Code Book”. Helmers Publishing

Rouillard, J. (2008). Contextual QR Codes, Proceedings of the Third International Multi-Conference on Computing in the Global Information Technology.

Stephen Few. 2006. Information Dashboard Design, Orrely.

Venkatesh, J. 2007. An introduction to Total Productive Maintenance (TPM). 